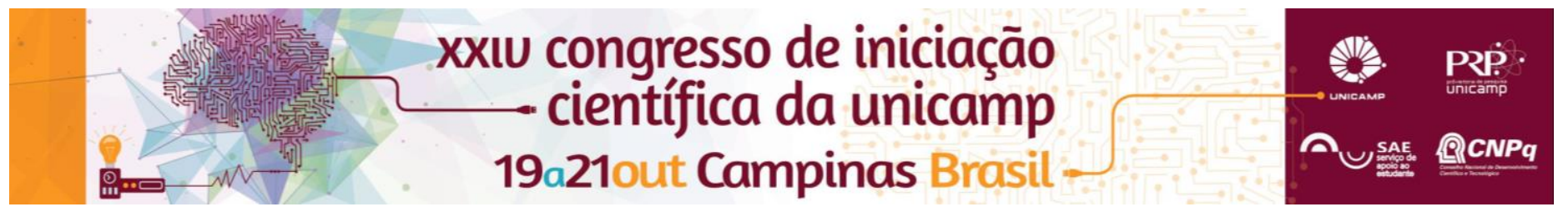

\title{
Possibilidades de diálogo entre a formação de atores e a prática do Yoga.
}

\section{Natalia Ruggiero Colombo*}

\begin{abstract}
Resumo
Este trabalho visa realizar uma primeira aproximação ao vasto campo de pesquisa existente sobre as possíveis relações entra a prática de Yoga e a pedagogia do ator. Para isso, realiza um estudo teórico da bibliografia central do diretor russo Konstantin Stanislavski, e de alguns de seus comentadores, atentando-se às alusões à filosofia e prática do Yoga.
\end{abstract}

\section{Palavras-chave}

Teatro, Yoga, Formação de atores.

\section{Introdução}

Ao colocar o ator como figura central da arte teatral, muitos artistas contemporâneos vem registrando e pesquisando a necessidade deste em trabalhar sobre si mesmo de modo a preparar-se para, além de dominar técnicas expressivas necessárias à sua arte, atingir um estado de presença e concentração em cena que o possibilite atuar de maneira psicofísica. A constante tensão entre aquilo que se passa interna e externa, mental e fisicamente, durante o trabalho do ator é algo que saltou aos meus olhos logo nos primeiros anos de graduação em Artes Cênicas e, naturalmente, comecei a relacionar a minha prática pessoal de Hatha Yoga às questões que vinha enfrentando como atriz. Diante disso, este trabalho tem como objetivo realizar uma primeira aproximação à ampla discussão existente na contemporaneidade sobre as possibilidades de diálogo entre a prática do Yoga e a pedagogia do ator. Para isso, concentra-se na bibliografia central do diretor russo Konstantin Stanislavski, realizando um estudo que relaciona a pedagogia de ator apresentada por ele à filosofia, prática e conceitos próprios do Yoga.

\section{Resultados e Discussão}

Realizou-se inicialmente um estudo sobre a própria disciplina yogui através das obras Yoga: imortalidade e liberdade, de Mircea Eliade e Os Yoga Sutras, de Patanjali, com os quais Eliade dialoga intimamente. Optou-se pelo estudo das obras de Konstantin Stanislavski em sua tradução espanhola, uma vez que esta tenha sido realizada diretamente do russo, enquanto que a versão portuguesa foi traduzida do inglês, de maneira a não perder determinados conceitos relacionados ao Yoga que podem ter sido excluídos devido aos interesses específicos dos Estados Unidos pela obra. Ao longo do estudo de El trabajo del actor sobre sí mismo en el proceso creador de la encarnación e El trabajo del actor sobre sí mismo en el proceso creador de la vivencia, notou-se a semelhança de objetivos entre os exercícios corporais e de respiração diários que Tortsov propunha a seus alunos e determinados asanas e pranayamas, propostos pelo Hatha Yoga. Nestas obras, Stanislavki também aborda fortemente a questão ética que envolve o trabalho do ator dialogando diretamente com conceitos da filosofia yogui como os yamas, principalmente no que diz respeito a relação do indivíduo com o próprio ego. É possível realizar, ainda, o paralelo entre demais conceitos stanislavskianos como Círculos de Atenção; Imaginação; Concentração; e Relaxamento Muscular com conceitos/habilidades trabalhados no Hatha Yoga como Atenção Múltipla; Foco; Meditação; Visualização; e Relaxamento.

\section{Conclusões}

Nota-se que o principal ponto de contato entre o pensamento yogui e a maneira como Stanislavski pensa a pedagogia do ator está na crença sedimentada de que há uma forte relação entre o corpo e a mente e de que o externo atua sobre o interno e vice-versa. Segundo o diretor russo o ator realiza sua criação tanto interior quanto externamente e depende de um "aparato físico" que seja capaz de responder formalmente à demanda de toda vida de seu "yo-interior". O Hatha Yoga, portanto, mostra-se bem-vindo no trabalho do ator sobre si mesmo, na medida em que, como discutido ao longo do trabalho, possibilita o desenvolvimento de consciências e sensibilidades afins ao processo criativo do artista, não apenas como profissional, mas também como ser humano. O campo de artistas que se interessam pelas práticas orientais e se relacionam de alguma forma com elas é significativo e vai de Konstantin Stanislavski e Jerzy Grotowski, até contemporâneos como Phillip Zarrilli e Ariane Mouchkine. Realizar uma aproximação a estas pesquisas se torna relevante na medida em que, como constatado neste trabalho, estas práticas podem oferecer a artistas ocidentais o desenvolvimento de percepções pouco exploradas em nossas práticas habituais.

\section{Agradecimentos}

Agradeço a meu orientador Prof. Dr. Cassiano Sydow Quilici por me ajudar a realizar a ponte entre o Yoga e o Teatro, e a Naira Rodrigues por me guiar no descoberta do Yoga. Pesquisa financiada pelo PIBIC - Programa Institucional de Bolsas de Iniciação Científica e Tecnológica da UNICAMP.

Eliade, M. Yoga: Imortalidade e Liberdade. São Paulo: Palas Athena, 1996.

Patanjali. Os Yoga Sutra de Patanjali. São Paulo: Mantra, 2015

Stanislavski, K. El trabajo del actor sobre si mismo en el proceso creador de la encarnación. Madri: Alba, 2003.

Stanislavski, K. El trabajo del actorsobre si mismo en el proceso creador de la vivencia. Madri: Alba, 2003. 